\title{
Correction to: HiComet: a high-throughput comet analysis tool for large-scale DNA damage assessment
}

Taehoon Lee', Sungmin Lee', Woo Young Sim², Yu Mi Jung ${ }^{3}$, Sunmi Han ${ }^{3}$, Joong-Ho Won ${ }^{4}$, Hyeyoung Min ${ }^{5}$ and Sungroh Yoon ${ }^{1,6^{*}}$

\section{Correction}

Due to an error introduced during typesetting of this article [1], the author affiliations have been accidentally omitted in the PDF. The author affiliations can be found in this correction:

1. Department of Electrical and Computer Engineering, Seoul National University, 08826 Seoul, Korea.

2. R\&D Center, Wearable Healthcare, 16954 Gyeonggi-do, Korea.

3. Research Division, NanoEnTek, 08389 Seoul, Korea.

4. Department of Statistics, Seoul National University, 08826 Seoul, Korea.

5. College of Pharmachy, Chung-Ang University, 06974, Seoul Korea.

6. Bioinformatics Institute, Seoul National University, 08826 Seoul, Korea.

\begin{abstract}
Author details
${ }^{1}$ Department of Electrical and Computer Engineering, Seoul National University, Seoul 08826, Korea. ${ }^{2}$ R\&D Center, Wearable Healthcare, Gyeonggi-do 16954, Korea. ${ }^{3}$ Research Division, NanoEnTek, Seoul 08389, Korea. ${ }^{4}$ Department of Statistics, Seoul National University, Seoul 08826, Korea. ${ }^{5}$ College of Pharmachy, Chung-Ang University, Seoul 06974, Korea. ${ }^{6}$ Bioinformatics Institute, Seoul National University, Seoul 08826, Korea.
\end{abstract}

Received: 2 May 2018 Accepted: 2 May 2018

Published online: 11 May 2018

\section{Reference}

1. Lee T, Lee S, Sim WY, Jung YM, Han S, Won J, Min H, Yoon S. HiComet: a

high-throughput comet analysis tool for large-scale DNA damage assessment. BMC Bioinformatics. 2018;19(Suppl 1):44. https://doi.org/10. 1186/s12859-018-2015-7.

\footnotetext{
* Correspondence: sryoon@snu.ac.kr

${ }^{1}$ Department of Electrical and Computer Engineering, Seoul National University, Seoul 08826, Korea

${ }^{6}$ Bioinformatics Institute, Seoul National University, Seoul 08826, Korea

Full list of author information is available at the end of the article
}

(c) The Author(s). 2018 Open Access This article is distributed under the terms of the Creative Commons Attribution 4.0 International License (http://creativecommons.org/licenses/by/4.0/), which permits unrestricted use, distribution, and reproduction in any medium, provided you give appropriate credit to the original author(s) and the source, provide a link to the Creative Commons license, and indicate if changes were made. The Creative Commons Public Domain Dedication waiver (http://creativecommons.org/publicdomain/zero/1.0/) applies to the data made available in this article, unless otherwise stated. 